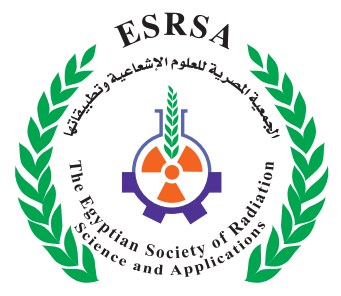

J. Nucl. Tech. Appl. Sci., Vol. 7, PP. 9 : 21 (2019)

\title{
The Protective Role of Garlic Aqueous Extract (Allium sativum) against 950MHz Electromagnetic Field Induced Rats Brain Damage
}

Shoman, H.M. ${ }^{1}$; El Sayed, R.A. ${ }^{1}$; El-Tahawy, N.A. ${ }^{2}$ \& Nasef, E.M. ${ }^{1}$

Received: 28/09/2018

Accepted: 06/11/2018

E.mail:esraakotb_nasef@yahoo.com

\section{KEYWORDS}

Garlic, Radiation, Oxidative Stress, Neurotransmitters, Brain Tissue.

\section{ABSTRACT}

Over the past several decades, people have been constantly exposed to electric and magnetic fields from both industrial and domestic uses. The present study was designed to investigate the possible protective effect of garlic aqueous extract on oxidative stress, neurotransmitters and histological changes in the brain of male albino rats exposed to extremely electromagnetic fields (EMFs). In this experimental study, Forty male albino rats were divided into four equal groups: control; garlic $(500 \mathrm{mg} /$ $\mathrm{Kg}$ b.w); irradiated (exposed to the $950 \mathrm{MHz}$ electromagnetic field for one hour); garlic-irradiated (received garlic extract half an hour before EMF exposure). The garlic extract administration and EMF exposure were three times per week (day after day) for 7 weeks. The result of the present study showed that exposure to EMF provoked oxidative stress in the brain tissues notified by significant decreases of reduced glutathione (GSH) content associated with significant increase levels of malondialdehyde (MDA) and nitric oxide (NO). Alteration of neurotransmitters was verified by significant decreases in the levels of dopamine (DA), norepinephrine (NE), and serotonin (SE). These alterations were associated with histological changes and deposition of B-amyloid in the brain cerebral cortex. Garlic administration significantly attenuated the brain biochemical disturbances and histological changes of the EMF exposed rats. According to the result obtained in the present study it could be concluded that exposure to EMF can cause biochemical and histological damage, and garlic can diminished these alterations, throughout enhancing the endogenous antioxidant defenses

1. Zoology Department, Faculty of Science, Girlıs Branch, Al-Azhar University, Cairo, Egypt.

2. Radiation Biology Department, National Center for Radiation Research and Technology, Egyptian Atomic Energy Authority, Cairo, Egypt. 


\section{INTRODUCTION}

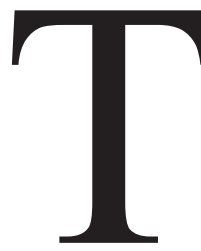

he electromagnetic fields are produced not only for technological applications (e.g., power lines mobile phones), but they are now widely used in medicine for diagnostic as magnetic resonance imaging (MRI), scanner and microwave imaging and therapeutic purposes (Hulbert et al., 1998). In 2002, the International Agency for Research on Cancer at World Health Organization (WHO) has classified the exposure to extremely low-frequency electromagnetic fields as a possible increasing the risk of malignant brain tumor development and increased risk for childhood leukemia (Carlberg et al., 2018).

Increased EMFs exposure can disturb the cellular balance by generating reactive oxygen species (ROS) (Simkó, 2007). The interaction between the ELF-EMFs and the biological systems directly implies the involvement of the oxidative stress (O'Dea et al., 2005), that occurs when the antioxidant defense system is unable to prevent the harmful effects of the free radicals (Thakare and Utane, 2018). Neurotransmitters are chemical substances that work as messengers conduct information throughout body and brain, in addition to carrying and tuning the signals between nerve cells and other cells affecting brain function. Consequently, these neurochemicals can be used to investigate the brain function (EI Sayed and Mohamed, 2017). Exposure to electromagnetic field can cause neurodegenerative disease as Alzheimer disease, parkinson disease. Beta amyloid deposition and neuro oxidative stress are two important features of Alzheimer disease (AD) that may influence its progression (Hauss-Wegrazyniak and wenk, 2002). The brain, organ is more sensitive to oxidative damage (Özmen et al., 2007). Therefore, it is key issue to assess the prompted changes in the levels of neurotransmitter and brain oxidative stress parameters as an outcome to EMFs exposure that can infer many of the living organism cognitive status.
Many efforts have been undertaken in evaluating the relative potential role of natural compounds to minimize the deleterious effects of the environmental pollutants. As a member of the Liliaceous family, Allium sativum or garlic contains various vital substances including minerals, carbohydrates, proteins, fats and vitamins (Ulbricht et al., 2010). Traditionally, garlic is used for its cytotoxic, antitumor, antifungal, antiviral and antiprotozoal properties (Sarkar et al., 2006 and Verma and Pandey, 2017). Garlic also used as a therapeutic agent for many different diseases such as hypertension, hypercholesterolemia, diabetes, atherosclerosis, and cancer (Konrad et al., 2018).

Despite extensive researches for studying EMF effects on the human body (Pall, 2016 and Carlberg et al., 2018), the majority of these studies only investigated the effects of EMF waves but the strategies about how to reduce these effects is still an important point of research. The present study was designed to investigate the influence of garlic on oxidative stress, neurotransmitters and histological changes in the brain of male albino rats exposed to EMF.

\section{MATERIALS AND METHODS}

\section{Animals}

Forty adult male albino rats of Sprague- Dawley strain aged 6 weeks with an initial weight of 100-120 $\mathrm{g}$ at the beginning of the experiment were obtained from the animal house of the National Center for Radiation Research and Technology (NCRRT), Atomic Energy Authority, Nasr City, Cairo, Egypt. Animals were kept under standard laboratory housing conditions, allowed free access to water and conventional diet and drinking water ad libitum, and acclimatization one week before onset of the experiment. All animal treatment procedures conform the National Centre for Radiation Research and Technology (NCRRT), Cairo, Egypt, and in accordance with the guidelines of the proper care and use of laboratory animals. 


\section{Garlic preparation}

Fresh Garlic was purchased from a local grocery store. The garlic extract was prepared according to the method reported by Alnaqeeb et al. (1996). Briefly, the fresh garlic cloves were peeled on crushed ice, and $50 \mathrm{~g}$ of garlic was homogenized in $75 \mathrm{ml}$ of cold, distilled water in the presence of some crushed ice. The filtered homogenized mixture was then centrifuged at $2000 \mathrm{rpm}$ for $10 \mathrm{~min}$ and the clear supernatant was made up to $100 \mathrm{ml}$ with distilled water. The concentration of the garlic preparation was considered to be $500 \mathrm{mg} / \mathrm{ml}$. The prepared garlic extract was stored at $-20^{\circ} \mathrm{C}$ until used.

\section{Exposure system}

A specially designed electromagnetic field (EMF) exposure system was used to produce EMF with a frequency equal to $950 \mathrm{MHz}$ (mobile phone radiation). The animals were kept in a special cage for irradiation with EMF, then a vertical electromagnetic induction was applied to the whole body of the animal. Irradiation of the rats was carried out at the National Center for Radiation Research and Technology (NCRRT), Atomic Energy Authority, Nasr City, Cairo, Egypt..

\section{Experimental design}

Male albino rats were equally divided into four groups (10 rats in each group) as follows; group I (Control group), group II (Garlic group): rats orally received $500 \mathrm{mg} / \mathrm{kg}$ b.w. of garlic extract three times per week (day after day) for seven weeks.

Group III (Irradiated group), rats were exposed to $950 \mathrm{MHz}$ EMF for one hour three times per week (day after day) for seven weeks. Group IV (Garlic - Irradiated group), rats orally administered with $500 \mathrm{mg} / \mathrm{kg}$ b.w. of garlic extract and exposed to $950 \mathrm{MHz}$ EMF for one hour three times per week (day after day) for seven weeks after half an hour of garlic dosage.
Animals were kept fasting before anesthetized with diethyl ether at the end of the experiment.

Brains were rapidly excised, washed in ice-cold saline, perfused with the same solution to remove blood cells, blotted on filter paper, weighed and quickly divided into two halves. The first half was homogenized in a $10 \%(\mathrm{w} / \mathrm{v}) 0.1 \mathrm{M}$ Tris buffer $(\mathrm{pH}$ 7.4) and centrifuged at $10,000 \mathrm{rpm}$ for 30 minutes at $4{ }^{\circ} \mathrm{C}$ using Sigma $3 \mathrm{~K} 30$ cooling centrifuge (Germany) and the clear supernatant was collected for the antioxidant and neurotransmitters parameters estimation. Malondialdehyde (MDA), Reduced glutathione (GSH) and Nitric oxide (NO) were determined in both the sera and brain homogenates as markers for oxidative stress, using commercial kits based on the methods described by Ohkawa et al. (1979), Beutler et al. (1963) and Montgomery and Dymock (1961), respectively. Serotonin (5-HT), dopamine (DA) and norepinephrine (NE) levels were measured in the brain homogenates using HPLC according to Abdel-Salam et al. (2011) to explore the changes in the neurotransmitters.

For histological examination, the second half of brains were divided and preserved in different fixatives. Sections were stained with Haematoxylin and Eosin stain according to Lillie (1965), as well as congo red stain according to Klunk et al. (1999). The optical density of histochemical stained sections in brains of the control and treated groups was recorded using IPWIN 32 image analysis software.

\section{Statistical analysis}

The results were expressed as Mean \pm SEM (standard error of the mean). Data analysis was performed with one-way ANOVA using the statistical Package for Social Sciences (SPSS) program, version 23. Post hoc test was used to assess differences between means. A significant difference for all statistical analysis was considered at the level of $\mathrm{P} \leq 0.05$. 


\section{RESULTS}

Brain biochemistry analysis was performed for the control and all treated groups to investigate the influence of garlic on oxidative stress and neurotransmitters changes in male albino rats exposed to EMF.

The data illustrated in Fig. (1): Showed Garlic group (II) revealed non-significant change in brain tissues NO and MDA levels while garlic affect GSH by increasing its level significantly $(\mathrm{p}<0.05)$ as compared to the control group (Fig. 2). On the other hand, significant increase $(p<0.05)$ in NO and MDA levels with highly significant decrease $(p<0.05)$ in the GSH levels were reported in the irradiated group (III) as compared to the control group. However, group (IV) showed significant decrease in the levels of NO and MDA associated with significant increase in GSH levels as compared to irradiated group (III). Interestingly, garlic administration returned values of these parameters in brain tissues to be near the normal range as compared to the control group (Fig.1).

Furthermore, the present results indicated that garlic significantly increased the dopamine and norepinephrine levels as compared to the control group (Figs.2\&3). Interestingly, the garlic repairing effect were obviously pronounced in group (IV) by reversing the decreased effect of ELF-EMF on the dopamine and norepinephrine levels and brought their values to be very close to the control group (Figs.2\&3). On the other hand, there was non significant increase in the serotonin level in the garlic group (group II), however its level were significantly decreased $(p<0.001)$ in the irradiated group as compared to the control group (Fig.4). The administration of garlic before radiation (group IV) recorded a significant increase $(p<0.05)$ in the serotonin levels as compared to irradiated group (III), however it was still significantly lower $(\mathrm{p}<0.05)$ than the control values (Fig.4).
The results illustrated in figs. (5\&6), showed the effect of EMF (group III) on the mean value of amyloid that was significantly increased and appeared by a densely stained cerebral cortex as compared to the control. In groups (II and IV) the effect of garlic clearly appeared where group (II) showed a significant decrease in the amyloid optical density value $(\mathrm{P} \leq 0.05)$ with less staining cerebral cortex compared to the control group. Meanwhile, in group (IV) garlic significantly decreased $(\mathrm{P} \leq 0.05)$ the amyloid optical density as compared to the irradiated and the control groups with less staining tissues (Figs. 5\&6).

\section{Histopathological examination of rat brains}

The cerebrum consists of an outer gray matter (cerebral cortex) and an inner white matter. The cerebral cortex is made up of nerve cells, nerve fibers, and neuroglia. Cerebral cortex of control group consists of six different layers: Molecular layer: it is the outer most layer, formed of nerve fibers and neuroglial element, the external (outer) granular layer having small stellate shaped nerve cells, the outer small pyramidal cell layer having small pyramidal cells, the internal (outer) granular layer formed of small stellate nerve cells, the inner pyramidal cell layer formed of large pyramidal cells and the polymorphic cell layer formed of nerve cells.

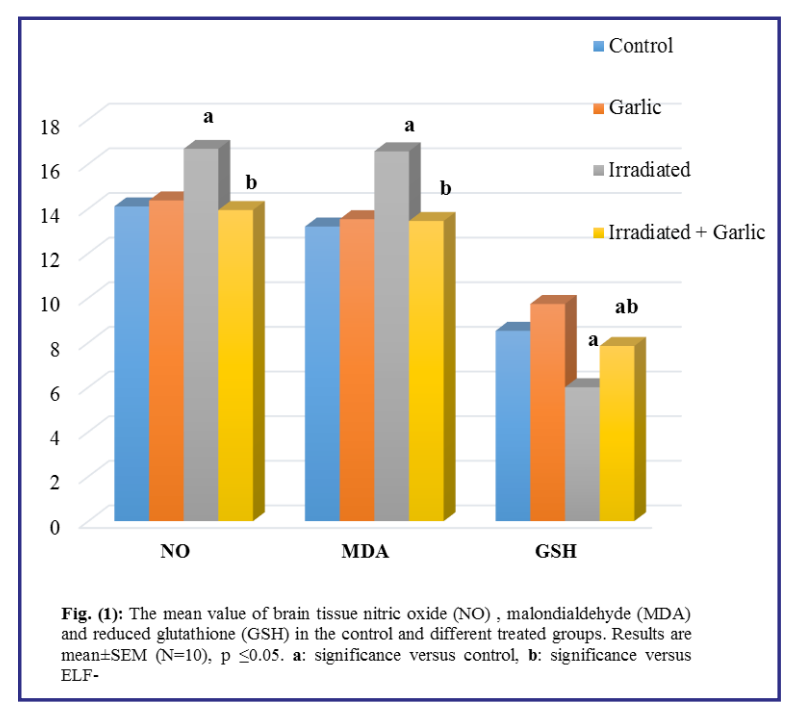


The histopathological examination of the brain tissue of the garlic group (II) showed the normal structure and appearance like in the control group. In irradiated group (III); the cerebral tissue showed histological changes, where some neuronal cells have abnormal, deformed and degenerated appearance. Vacuolated and necrotic spaces were also observed.
Also, in some parts a spongous appearance of neuropil was noted. In group received garlic before EMF (IV); the tissue appeared somewhat like the normal cerebral tissue, neuronal cells have a normal appearance, but some degeneration and necrotic spaces still appeared in the tissue.
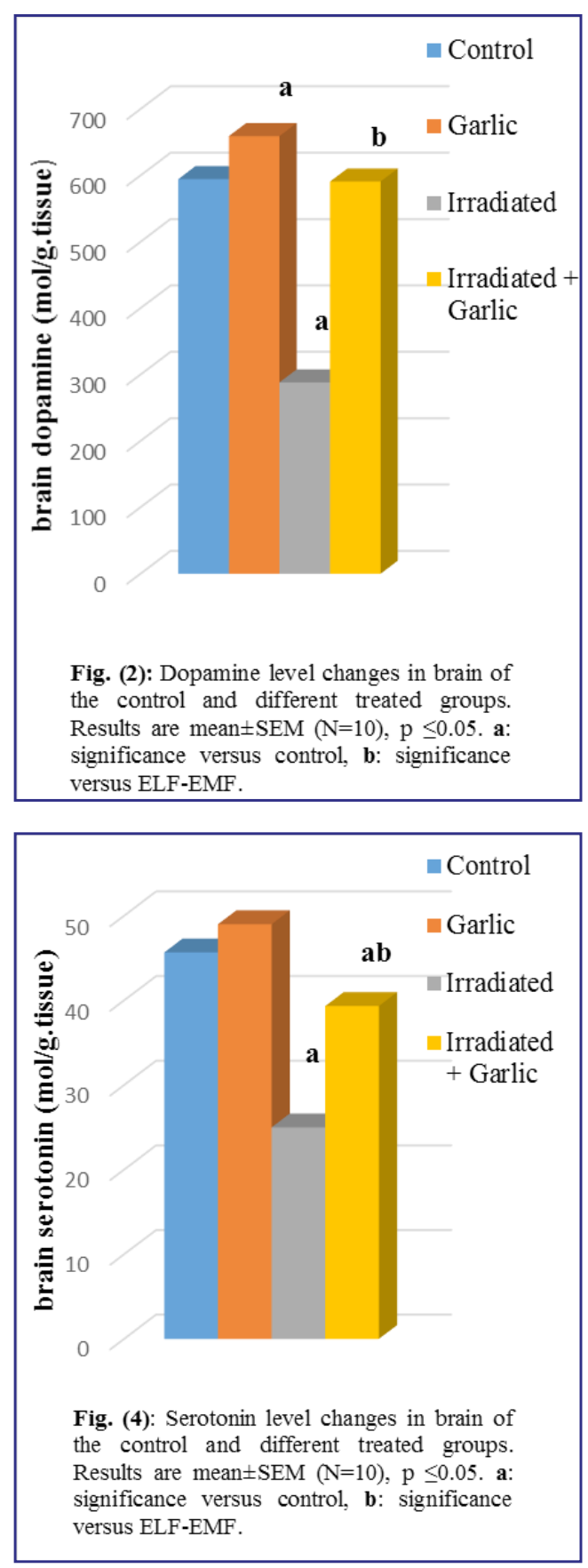
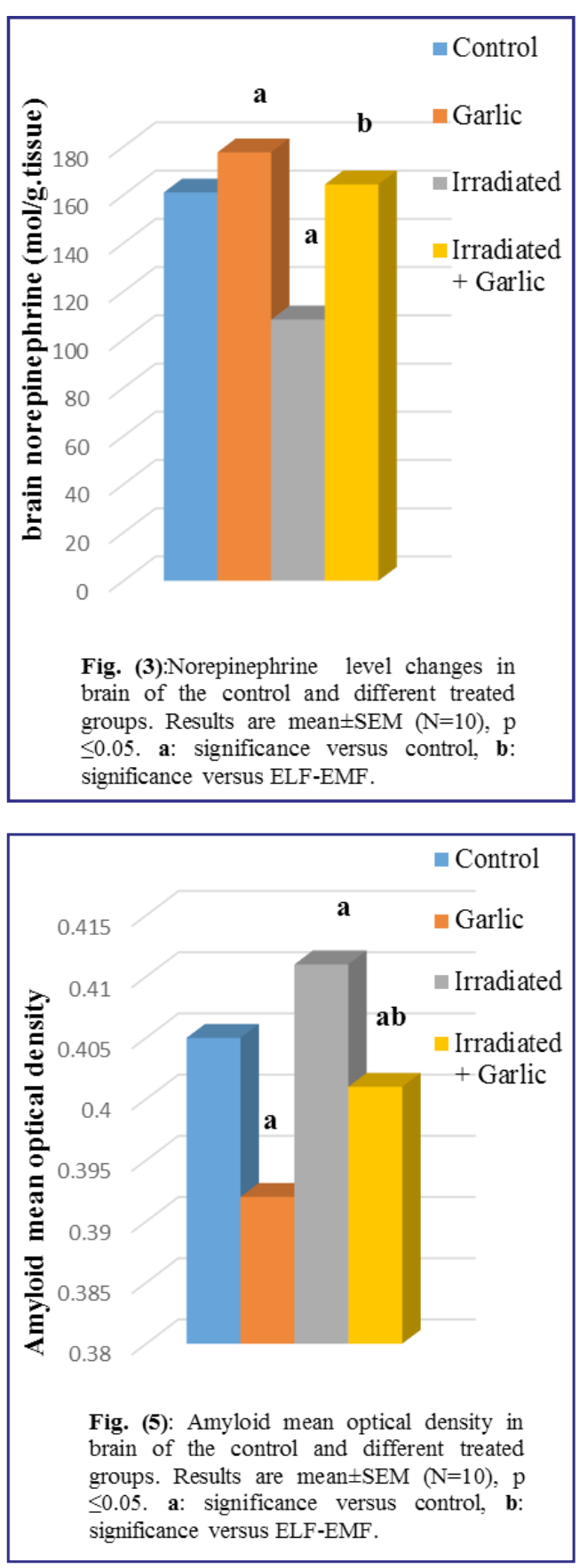


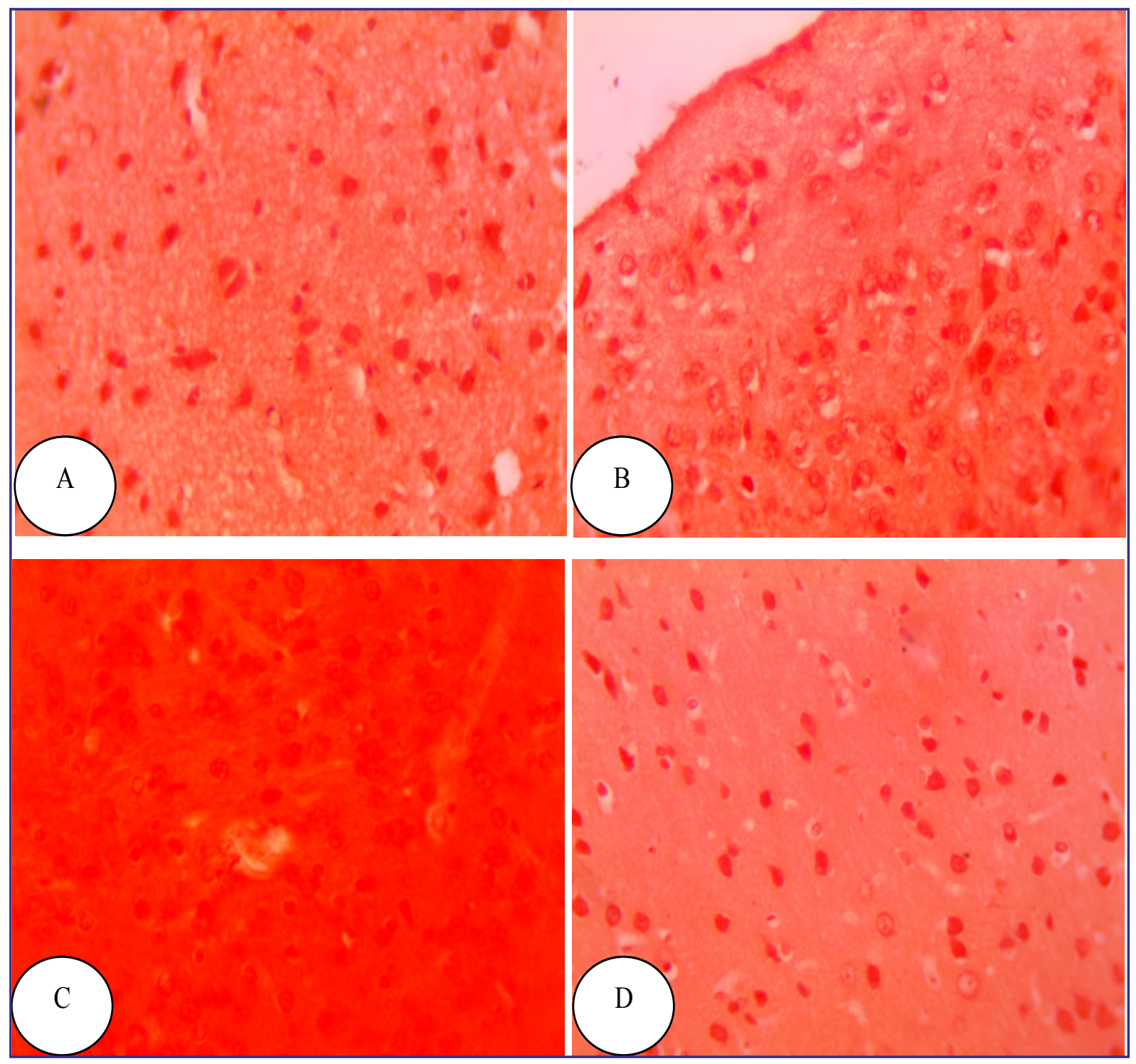

Fig. (6): Photomicrographs of the rat cerebral cortex. (A): group (I) showing normal distribution of the amyloid protein in brain tissue. (B): group (II) showing a decrease in the color density when compared with control, means less distribution of the amyloid protein in brain tissue. (C): group (III) showing a high increase in the color density when compared with control, means more distribution of the amyloid protein in brain tissue. (D): group (IV) showing less color density than control, means less distribution of the amyloid protein in brain tissue. (Congo red X100). 


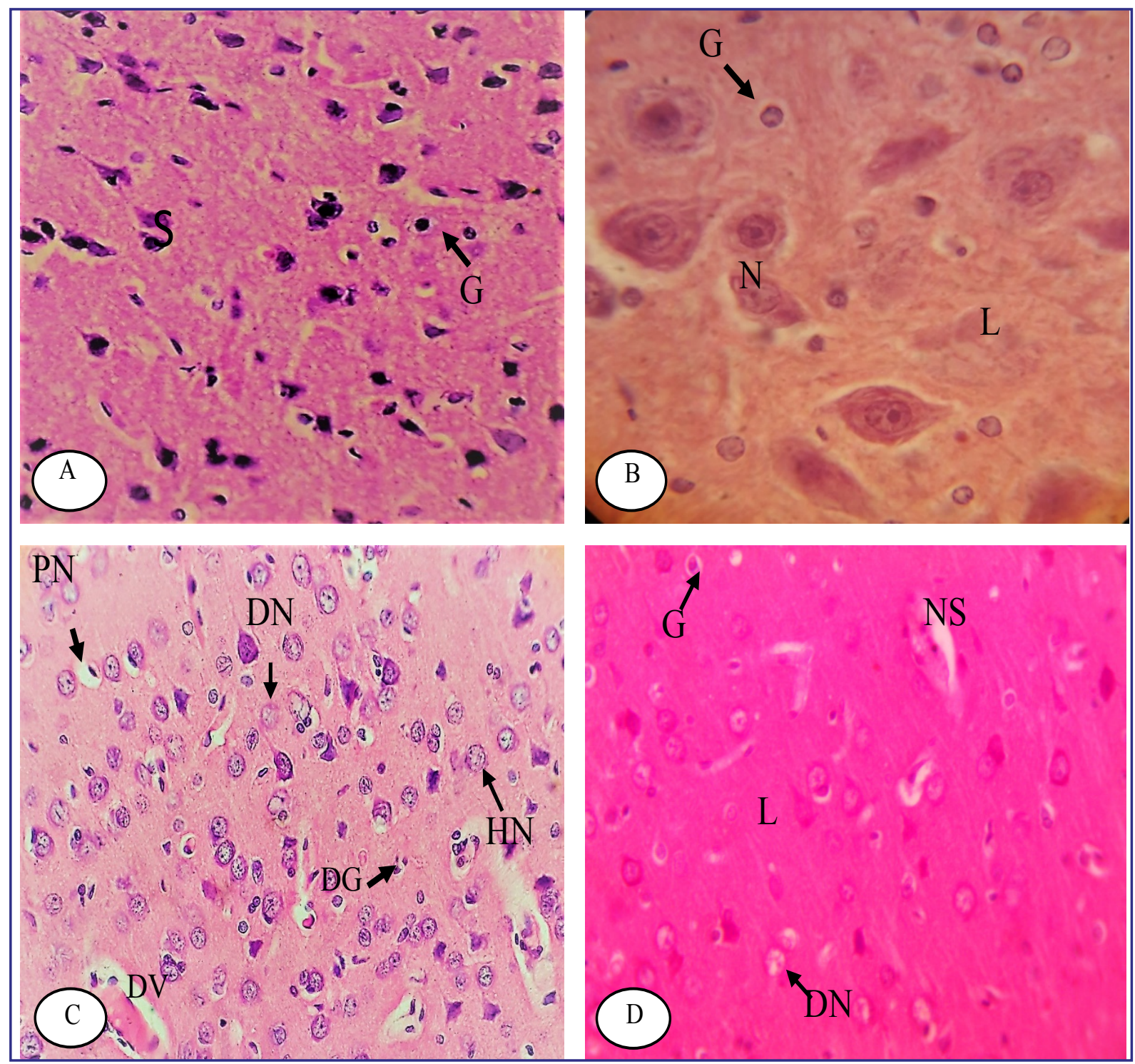

Fig. (7): Photomicrographs of the rat cerebral cortex in different groups.(A): Group(I) that showing stellate nerve cell(S), neuropil (L) and glial cells (G).(B): Group (II) showing normal appearance of: nerve cells (N), glial cells (G), and neuropil (L).(C): group (III) showing different alternations like: degenerated neurons (DN), necrotic spaces (NS) degenerated glial cells(DG), spongeos shaped neuropil (SL), heterochromatic nucleus (HN), dilated blood vessel (DV) and pyknoticneucli (PN). (D): group (IV) showing somewhat normal appearance, but degenerated neurons (DN) and necrotic spaces (NS) still noted necrotic spaces, normal glial cells $(\mathrm{G})$, normal neuropil appearance $(\mathrm{L})$ and normal neural cells $(\mathrm{N})$. (H \& E a, c, d X100; b X 400). 


\section{DISCUSSION}

Nowadays with extension and progress in telecommunication application of cellular phones and power transmitted lines, exposing to EMF is a global hazardous problem. The natural impacts of cell phone radiation stay disputable, despite of many years of utilization because of controversial results of the experimental studies especially on brain and its functions. This study was conducted to investigate the possible protective role of garlic on oxidative stress, neurotransmitters and histological changes in the brain of male albino rats exposed to the $950 \mathrm{MHz}$ electromagnetic field.

The present study revealed that long-term exposure of the whole body of the male albino rats to ELF-EMFs radiation induced a significant alteration in the oxidant/antioxidant status in the brain identified by a significant increase in the level of nitric oxide (NO) and malondialdehyde (MDA) which is a marker of lipid peroxidation. The study of Guler et al. (2008), who reported that low-frequency electric field showed potentially harmful effects on the living organism by enhancing the radical production indicated by a significant elevation in the MDA and NO levels. These changes indicate increased ROS production that may reflect the pathological process of EMF exposure (Fehmi et al., 2005). Meanwhile, Lai and Singh (2004) attributed the MDA and NO changes to imbalance in iron homeostasis that increase free iron levels and leads to formation of hydroxyl radicals via the Fenton reaction, followed by lipid peroxidation and calcium leakage from internal storage that trigger nitric oxide synthesis which is responsible for damage to DNA and other macromolecular districts.

Glutathione (GSH) is an endogenous antioxidant and an important cellular defense agent against oxidative damage as it reacts with the free radicals and reduces the entry of hydrogen peroxides into the cell (Zhao et al., 2001). Concerning to reduced glutathione (GSH), the present results strongly showed that the previously mentioned MDA and NO changes were accompanied by a significant decrease of reduced glutathione (GSH), compared to the control rats. This reduction level of GSH may possibly be explained by an elevated oxidation rate and use of GSH during the elimination of lipid and other peroxides (Aslan and Meral, 2007),

The results of the present study showed that ELF-EMFs exposure, provoked oxidative stress in rat brain tissues demonstrated by a significant decrease in tissue GSH content associated to a significant increase in the tissue MDA and NO levels, compared to their relative values in the control group. The decrease of antioxidants might result from cell membrane damage (Bertrand et al., 2016), as well as their utilization to neutralize the excess of ROS (Sun et al., 1998).

Garlic administration effectively alleviated the EMF induced oxidative stress, as evidenced by increased levels of GSH in serum and brain tissues. The protective property of garlic may be attributed to the presence of organosulfur compounds, which have antioxidant and detoxifying properties. (Munday and Munday, 2004). Also, garlic contains certain compounds such as germanium and selenium that play an important role in normalizing the oxygen utilization in the cells (Hussein et al., 2007).

The result of this study showed a highly significant decrease in neurotransmitters level of serotonin, dopamine, and norepinephrine in the group exposed to EMF. Such results are in harmony with those obtained by Herrera et al. (1995) who attributed this decrease to ileal mucosa damage by radiation that impair L-tyrosine absorption diminishes the production of DA and NE. However, Dlugos et al. (2009) related these changes to monoamine oxidase (MAO) dysfunction which is a rate-limiting enzyme responsible for the monoamines catabolism and found bounded to the outer membrane of mitochondria in most cell types in the body, because of its vital role in the inactivation of neurotransmitters. Moreover, the 
significant decrease in the level of serotonin (5-HT) recorded in the brain of irradiated rats in the current study might be attributed to the oxidants/ antioxidant imbalance as reported by Ismail et al. (2015).

Garlic extract administered to rats demonstrated a non-significant increase in serotonin level in the group that takes garlic only, where a highly significant reduction in the serotonin levels was detected in the EMF-treated group. A slight improvement declared in the group received garlic with EMF in serotonin level as compared to control. This is in agreement with Haider et al. (2008).

In the current study, garlic significantly increased the level of norepinephrine in the brain tissue and also decreased the effect of EMF by raising the level of norepinephrine near the normal range in the group received garlic before EMF exposure. These results are in accordance with Oi et al. (1995) who showed that norepinephrine concentration was significantly increased by garlic administration, and the increase was dose-dependent. On the other hand, Zhang et al. (1998) stated that Aged garlic extract (AGE) treatment prevents the reduction of antibody production responses, improved the deterioration of learning behavior, and restored the contents of norepinephrine, and choline acetyltransferase activity in the hypothalamus.

In addition, Pan et al. (2005) attributed this antidepressant-like activity of the garlic extract to inhibition of MAO activities resulting in an increase in the brain levels of monoamines. Meanwhile, Dhingra and Kumar (2008) suggested that garlic extract might produce an antidepressant-like effect through interaction with neurotransmitter receptors, thereby increasing the levels of norepinephrine, dopamine, and serotonin in the brain of mice. This may support the use of garlic as a food supplement for the enhancement of memory.

As regards the histopathological changes, the microscopic examination of the group exposed to
EMF showed different histological changes from the normal appearance of the brain sections. Some neuronal cells have abnormal, deformed and degenerated appearance, vacuolated and necrotic spaces as well as in some parts a spongeous appearance of the tissue were also noticed. These alterations support and confirm the current preceding antioxidant and neurotransmitter changes in rat brain. These results are in accordance with the work by Usikalu $\boldsymbol{e t}$ al. (2012) who investigated the effect of $900 \mathrm{MHz}$ $\mathrm{RF}$ radiation from digital mobile phone on the brain of albino rats. The results of the exposed rat's brain showed a marked congestion of the cerebral blood vessels and the presence of numerous spongiform vacuoles in the nerve cells.

In addition, Salford $\boldsymbol{e t}$ al. (2003) identified neuronal injury to the cortex, hippocampus and basal ganglia of the rats exposed for $2 \mathrm{~h}$ to EMFs of different wavelengths emitted by GSF mobile phones. These injuries represented in scattered or clustered dark neurons, commonly shrunken and dark stained, with loss of discernible internal cell structures. In contrast, Daniels et al. (2009) and Khalil et al. (2012) demonstrated that $900 \mathrm{MHz}$ GSM-like RF radiation did not cause significant histological changes in the brain sections.

Interestingly, the microscopic examination of the brain tissue of the group received garlic before EMF (IV), the tissue appeared somewhat like the normal, but some degeneration and necrotic spaces still appeared. As well as, the group received garlic only showed normal structure and appearance and normal distribution of collagen fibers. These results are in aggrement with Borek (2006), who illustrated that aged garlic extract (AGE) has the potential to protect the brain against neurodegenerative conditions, by preventing brain injury following ischemia. Moreover, treatment with AGE or S-allyl cysteine has been shown to prevent the degeneration of the brain's frontal lobe, improve learning and memory retention, and extend lifespan as demonstrated by 
Nishiyama et al. (1997).

In the same time, in this study the B-amyloid showed significant increase in the group exposed to EMF as compared to the control, these results come in agreement with Jiang et al. (2013) who showed that rats exposed to 100,1000 , and 10,000 pulses EMP (field strength $50 \mathrm{kV} / \mathrm{m}$, repetition rate $100 \mathrm{~Hz}$ ) have cognitive and memory impairment where immune-histochemical staining showed increased betaamyloid protein $(\mathrm{A} \beta)$ in EMP exposure groups compared with the control group. In addition, Jackson et al. (2003) revealed the garlic role in preventing $\beta$-amyloid-induced oxidative death. Furthermore, Del et al. (2007) examined the effect of exposure to $3.1 \mathrm{mT} 50 \mathrm{~Hz}$ LF-EMF on amyloid-beta peptide secretion in cultured human neuroglioma and showed that overnight exposure to LF-EMF induces a significant increase of amyloid-beta peptide secretion, without affecting cell survival. These findings show for the first time that exposure to LF-EMF stimulates amyloid-beta peptide secretion in vitro, thus showing a potential link between LF-EMF exposure and amyloid-beta peptide APP processing in the brain. On contrary, Zhang et al. (2015) indicated that short-term exposure of $100 \mu \mathrm{T} / 50 \mathrm{~Hz}$ ELF-EMF had no effects on cognition and memory of rats, and did not alter the expression of $\beta$-amyloid (A $\beta)$ and the neuron morphology.

In the present study, garlic induced a significant decrease in the B-amyloid in the group received garlic only as compared to the control group. In addition, garlic diminished the effect of EMF on amyloid by decreasing its level significantly in the group received garlic before EMF. These results are in agreement with Gupta et al. (2009) who examined in vitro the anti-amyloidogenic properties of the aqueous fresh garlic extract $(100 \mu \mathrm{g} / \mathrm{mL})$. This extract not only inhibited $\mathrm{A} \beta$ fibril formation in a concentration and time-dependent manner but was also able to defibrillate $A \beta$ preformed fibrils. The maximum defibrillation was observed after 2-3 days of incu- bation. These findings suggest that consumption of garlic may lead to inhibition of $A \beta$ aggregation in the human brain.

In addition, Nillert et al. (2017) indicated that 250 and $500 \mathrm{mg} / \mathrm{kg}$ doses of AGE significantly improved short-term recognition memory in cognitively impaired rats ( $\beta$-amyloid-induced rats), also significantly minimized the induced inflammatory response to the levels of the control. In conclusion, AGE may be useful for improving the short-term recognition memory and relieve the neuroinflammation in $\mathrm{A} \beta$-induced rats.

It could be concluded that garlic aqueous extract offer protection against biochemical and histological disorders caused by exposure to EMF in brain tissues. Therefore, it is suggested that garlic could be a good supplementary food for prevent cognitive decline by protecting brain from $\mathrm{AB}$ neurotoxicity and possibly by enhancing the endogenous antioxidant defenses.

\section{REFERENCES}

- Abdel-Salam, O.M.; Salem, N.A. and Hussein J.S. (2011): Effect of aspartame on oxidative stress and monoamine neurotransmitter levels in lipopolysaccharide-treated mice. Neurotoxicology., 11:9264.

- Alnaqeeb, M.A.; Thomson, M.; Bordia, T. and Ali, M. (1996): Histopathological effects of garlic on liver and lung of rats. Toxicol.Lett., 85: 157.

- Aslan, L. and Meral, I. (2007): Effect of oral vitamin E supplementation on oxidative stress in guinea-pigs with short-term hypothermia. Cell Biochem. Funct., 25(6):711.

- $\quad$ Bertrand, K.F.; Pascal, C.D.; Paul, D.D. (2016): Protective Effect of Aged Garlic Extract Against the Oxidative Stress Induced by Acute Ionizing Irradiation on Hepatic Antioxidant Enzymes in Rats. EJCBS., 2(6): 69.

- Beutler, E.; Duron, O. and Kelly B.M. (1963): Improved method for the determination of blood gluta- 
thione. J. Lab. Clin. Med.; 61: 882-888.

- Borek, C. (2006): Garlic reduces dementia and heart-disease risk. J. Nutr., 136 (3):810S.

- Carlberg, M.; Koppel, T.; Ahonen, M. and Hardell, L. (2018): Case- Control Study on Occupational Exposure to Extremely Low-Frequency Electromagnetic Fields and the Association with Meningioma. BioMed. Research International, Article ID 5912394, 6 pages.

- Daniels, W.M.; Pitout, I.L.; Afullo, T.J.O. and Mabandla M.V. (2009): The effect of electromagnetic radiation in the mobile on phone range the behavior of the rat. Metab. Brain. Dis., DOI 10.1007/s11011009-9164-3.

- Del, E.; Facchinetti, F.; Nofrate, V.; Boccaccio, P.; Minelli, T.; Dam, M.; Leon, A. and Moschini, G. (2007): Fifty Hertz electromagnetic field exposure stimulates secretion of beta-amyloid peptide in cultured human neuroglioma. Neurosci. Lett., 418(1):9.

- Dhingra, D. and Kumar, V. (2008): Evidence for the involvement of monoaminergic and GABAergic systems in antidepressant-like activity of garlic extract in mice. Indian. J. Pharmacol., 40(4): 175.

- Dlugos, A.M.; Palmer, A.A.; and de Wit, H. (2009): "Negative emotionality: monoamine oxidase $\mathrm{B}$ gene variants modulate personality traits in healthy humans". J. Neural. Transm., 116 (10): 1323.

- $\quad$ El Sayed, R.A. and Mohamed, A.F. (2017): Assessment of neurological toxicity of gold sphere and rod nanoparticles used as adjuvant to Rift Valley Fever Virus vaccine (RVFV) and related physiological changes: In vivo study. Eur. J. Biom. and Pharma. Sci., 4(7):112.

- Fehmi, O.; Favuk, O.; Ali, A.; Ahmet, K. and Ramazan, Y. (2005): A novel antioxidant agent caffeic acid phenyl ester prevents long-term mobile phone exposure- induced renal impairment in the rat. Mol. Cell Biochem., 277: 73.

- Guler, G.; Turkozer, Z.; Tomruk, A.; and Seyhan, A. (2008): The protective effects of N-acetyl- L- cysteine and epigallocatechin- 3-gallate on electric field induced hepatic oxidative stress. Int. J. Radiat. Biol., 84 (8): 669.

- Gupta, V.B.; Indi, S.S. and Rao K.S.J. (2009): Garlic Extract Exhibits Antiamyloidogenic Activity on Amyloid-beta Fibrillogenesis: Relevance to Alzheimer's disease. Phytother. Res., 23:111.

- Haider, S.; Naz, N.; Khaliq, S. and Perveen, T. (2008): Repeated administration of fresh garlic increases memory retention in rats. J. Med. Food, 11(4):675.

- Hauss-Wegrazyniak, B. and wenk, G.L. (2002): Beta-amyloid deposition in the brains of rats chronically infused with thiorphan or lipopolysaccharide: the role of ascorbic acid in the vehicle. Neurosci. Lett., 322(2):75.

- Herrera, J.; Vigneulle, R.G.; MacVittie, T.; Nold, T.J. and Dubois, A. (1995): Effect of radiation and radioprotection on small intestinal function in canines. Dig. Dis. Sci., 40:211.

- Hulbert, A.; Metcalfe, J.C.; and Hesketh, R. (1998): "Biological responses to electromagnetic fields," The FASEB Journal., 12(6): 395.

- Hussein, J.S.; Oraby, F.S and El-Shafey, N. (2007): Antihepatotoxic Effect of Garlic and Onion Oils on Ethanol-induced Liver Injury in Rats, JASR., 3(11): 1527.

- Ilhan, A.; Gurel, A. and Armutcu, F. (2004): “Ginkgo biloba prevents mobile phone-induced oxidative stress in rat brain," Clinica. Chimica. Acta., 340(12):153.

- Ismail, S.A; Ali R.F.; Hassan, H.M. and Abd ElRahman, D. (2015): Effect of Exposure to Electromagnetic Fields (EMFs) on Monoamine Neurotransmitters of Newborn Rats. Biochem. Physiol., 4:156.

- Jackson, R.; McNeil, B.; Taylor, C.; Holl, G.; Ruff, D. and Gwebu, E. (2003): Effect of aged garlic extract on human recombinant caspase-3 activity. J. Ala. Acad. Sci., 74: 121.

- Jiang, D.P.; Li, J.; Zhang, J.; Xu, S.L., Kuang, F.; Lang, H.Y.; Wang, Y.F.; An, G.Z.; Li, J.H. 
and Guo, G.Z. (2013): Electromagnetic pulse exposure induces overexpression of beta-amyloid protein in rats. Arch Med. Res., 44(3):178.

- Khalil, A.; Al-Adhami, M.; Al-Shara, B.; Gagaa, M.; Rawshdeh, A. and Alshamli, A. (2012): Histological and ultrastructural analyses of male mice exposed to mobile phone radiation. $J$. of Toxicology Review, 1(1): 1.

- Klunk, W.E. Robert, F. and Mason, P. (1999): Quantifying amyloid by congo red spectral shift assay. Methods Enzymol., 309:285.

- Konrad, A.; Szychowski, and Świeca, M. (2018): Characterization of Active Compounds of Different Garlic (Allium sativum L.) Cultivars. Pol. J. Food Nutr. Sci., 68(1): 73.

- Lai, H. and Singh, N.P. (2004): Magnetic-fieldinduced DNA strand breaks in brain cells of the rat. Environ. Health Perspcct., 112:687.

- Lillie, R.D. and Geer, J.C. (1965): Histochemical and experimental studies. Oxidative stress in guinea-pigs with short-term hypothermia Cell Biochem. Funct., 25: 711.

- Montgomery, H.A. and Dymock, J.F. (1961): the coloric method for $\mathrm{NO}_{2}$ determination. Analyst, 86 : 414.

- Munday, R. and Munday, C.M. (2004): Induction of phase II enzymes by aliphatic sulfides derived from garlic and onions: An overview. Methods Enzymol., 382: 449 .

- Nillert, N.; Pannangrong, W. and Welbat, J.U. (2017): Neuroprotective Effects of Aged Garlic Extract on Cognitive Dysfunction and Neuroinflammation Induced by $\beta$-Amyloid in Rats. Nutrients. Jan., 9(1): 24.

- Nishiyama, N.; Moriguchi, T. and Saito, H. (1997): Beneficial effects of aged garlic extract on learning and memory impairment in the senescence-accelerated mouse. Exp. Gerontol., 32: 149.

- O'Dea, A.R. ; Curtis, A.F. ; Green, N.J.B. ; Tinu- nel, C.R. and Hore, P.J. (2005): Influence of dipolar interactions on radical pair recombination reactions subject to weak magnetic fields, J. Phys. Chem. A., 109(5):869.

- Ohkawa, H.; Ohishi, N. and Yagi, K. (1979): Assay for lipid peroxidation in animal tissues by thiobarbituric acid reaction. .Ann. Biochem.., 95: 351.

- Oi, Y.; Kawada, T.; Kitamura, K. Oyama, F. (1995): Garlic supplementation enhances norepinephrine secretion, the growth of brown adipose tissue, and triglyceride catabolism in rats. $J$ of Nut. Biochem., 6(5): 250.

- $\quad$ Özmen, M.; Naziro $\square$ lu, H.A.; Alici, F.; Şahin, M.; Cengiz, and Eren, I. (2007): "Spinal morphine administration reduces the fatty acid contents in spinal cord and brain by increasing oxidative stress. Neurochem. Res., 32(1):19.

- Pall, M.L. (2016): Microwave frequency electromagnetic fields (EMFs) produce widespread neuropsychiatric effects including depression. $J$. of neuroanatomy, 75:43.

- Pan, S.L.; Xie, J.; Qian, F.G.; Wang, J.; Shao, Y.C. (2005): Antidepressant amides from Piper laetispicum. Yaо. Хие. Хие. Вaо., 40: 355.

- Saada, H.N. and Azab, K.S. (2001): Role of lycopene in the recovery of radiation-induced injury to mammalian cellular organelles. Pharmazie., 56 (3): 239.

- Salford, L.G.; Brun, A.E.; Eberhardt, J.L.; Malmgren, L and Bertil, R. (2003): Nerve cell damage in mammalian brain after exposure to microwaves from GSM mobile phones. Environ. Health Perspect., 111:881.

- Sarkar, P.; Kumar, H.; Rawat, M.; Varshney, V.P.; Goswami, T.K.; Yadav, M.C. and Srivastava, S.K. (2006): Effect of administration of garlic extract and PGF $2 \alpha$ on hormonal changes and recovery in endometritis cows. Asian Austral. J. Anim., 19: 964.

- Simkó, M. (2007): Cell type-specific redox status is responsible for diverse electromagnetic field effects, Curr. Med. Chem., 14(10):1141. 
- Sun, J.; Chen, Y.; Li, M. and Ge, Z. (1998): Role of antioxidant enzymes in ionizing radiation resistance. Free Radic. Biol. Med., 24: 586.

- Thakare, N.S., and Utane, A.S. (2018): Effect of Exposure of High Frequency Electromagnetic Field on Human Health: A. Inter. J. of Adv. Res. Electro. and Comm. Eng. (IJARECE)., 7(1):45.

- Ulbricht, C.; Basch, E. and Basch, S. (2010): An evidence-based review of garlic and its hypolipidemic properties by the natural standard research collaboration. Natural Med J.; 2(4): 1.

- Usikalu, M.R.; Rotimi, S.O. and Oguegbu, A.E. (2012): Effect of exposure of $900 \mathrm{MHz}$ radiofrequency radiation on rat brain. Europ. J. Experim. Biol., 2 (6):2499.

- Verma, S. and Pandey, A.K. (2017): Garlic Treatment to Brain Cancer: An In-silico Evaluation to Ex- plore the Therapeutic Efficacy of Allicin by Inhibition of Brain Aquaporin. J. In SilicoIn. VitroPharmacol., 3:21.

- Zhang, Y.; Moriguchi, T.; Saito, H. and Nishiyama, N. (1998): Functional relationship between agerelated immunodeficiency and learning deterioration, Eur. J. Neurosci., 10(12): 3869.

- Zhang, Y.; Liu, X.; Zhang, J. and Li, N. (2015): Short-term effects of extremely low-frequency electromagnetic fields exposure on Alzheimer's disease in rats. Int. J. Radiat. Biol., 91(1):28.

- Zhao, X.; Alexander, J.S.; Zhang, S.; Zhu, Y. and Sieber, N.J. (2001): Redox regulation of endothelial barrier integrity. Am J Physiol Lung Cell Mol. Physiol., 281: L879. 
